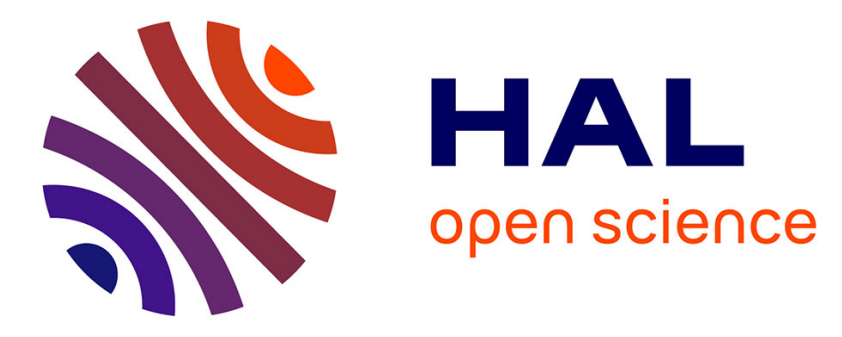

\title{
Understanding Changeability Enablers and Their Impact on Performance in Manufacturing Companies
}

Ann-Louise Andersen, Kjeld Nielsen, Thomas Ditlev Brunoe, Jesper K. Larsen, Christopher Ketelsen

\section{- To cite this version:}

Ann-Louise Andersen, Kjeld Nielsen, Thomas Ditlev Brunoe, Jesper K. Larsen, Christopher Ketelsen. Understanding Changeability Enablers and Their Impact on Performance in Manufacturing Companies. IFIP International Conference on Advances in Production Management Systems (APMS), Aug 2018, Seoul, South Korea. pp.297-304, 10.1007/978-3-319-99704-9_36 . hal-02164905

\section{HAL Id: hal-02164905 \\ https://hal.inria.fr/hal-02164905}

Submitted on 25 Jun 2019

HAL is a multi-disciplinary open access archive for the deposit and dissemination of scientific research documents, whether they are published or not. The documents may come from teaching and research institutions in France or abroad, or from public or private research centers.
L'archive ouverte pluridisciplinaire HAL, est destinée au dépôt et à la diffusion de documents scientifiques de niveau recherche, publiés ou non, émanant des établissements d'enseignement et de recherche français ou étrangers, des laboratoires publics ou privés.

\section{(c)(1)}

Distributed under a Creative Commons Attribution| 4.0 International License 


\title{
Understanding Changeability Enablers and their Impact on Performance in Manufacturing Companies
}

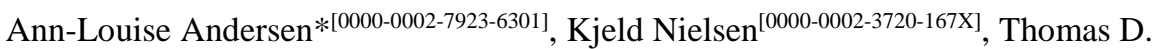 \\ Brunoe $^{[0000-0002-9847-6562]}$, Jesper K. Larsen ${ }^{[0000-0003-3440-4401]}$, Christopher Ketelsen ${ }^{[0000-}$ \\ 0003-1735-4617] \\ Department of Materials and Production, Aalborg University, Aalborg, Denmark \\ *ala@mp.aau.dk
}

\begin{abstract}
Managing and capitalizing on product variety, customization, personalization, decreasing batch sizes, as well as rapid new product introductions are prevailing challenges facing today's manufacturing companies. Changeable and reconfigurable manufacturing systems have been widely accepted as means to respond to these challenges, due to their ability to accommodate continuous and cost-efficient change in functionality and capacity. However, enablers of reconfigurability that should be selected during manufacturing system design are in current research rarely regarded in terms of their inherent relations and impact on manufacturing performance. Therefore, the aim of this paper is to explore implementation relations between physical enablers of reconfigurability on system and equipment level and their effect on manufacturing performance. For this purpose, a quantitative questionnaire-based survey has been conducted in various Danish manufacturing companies. The findings suggest that most reconfigurability enablers correlate strongly in their implementation and their extent of implementation generally correlates with critical performance aspects such as profitability, ramp-up time, and life-time of production systems.
\end{abstract}

Keywords: Changeable manufacturing, changeability, reconfigurable manufacturing; reconfigurability; survey research.

\section{Introduction}

Rapid market change driven by increasing global competition and technological innovation represents a prevailing challenge in manufacturing companies, whether it is in relation to change in product demand, change in product mix, or frequent introductions of new products [1], [2]. In order to respond to this challenge and sustain competitive advantage, manufacturing companies must develop manufacturing systems that can respond to change and adapt quickly to shifting customer needs [1]. However, at the same time manufacturing companies face increasing pressure for cost-efficiency and productivity, particularly in high-wage countries where extensive relocation of production has occurred in the recent decade [3]. This dichotomy between pressure for responsiveness and pressure for cost-efficiency is often recognized as the poly-lemma of production [3]. On one hand, high economies of scope and low planning-effort foster successful 
adaption, whereas on the other hand, high economies of scale and sophisticated planning methods result in optimal utilization of resources and high cost-efficiency [3]. Resolution of this poly-lemma between economies of scale and scope and between value and planning orientation is key to delivering not only customized and premium products to niche markets, but also in order to have near mass production efficiency and achieve sustainable competitive advantage [3].

In order to resolve the poly-lemma of production, changeable manufacturing systems appear promising. A changeable manufacturing system is defined as having the ability to accomplish early, foresighted, and economically feasible adjustments in all structures and processes in accordance with internal and external change requirements [1]. Depending on the requirements and strategy for change, this can be accomplished through flexibility, reconfigurability, or a combination of both [1]. Flexibility represents preplanned and built-in ability to change functionality and capacity with limited effort and without significant alterations of the system's existing structures, whereas reconfigurability represents functionality and capacity on demand through efficient alterations of existing physical and logical structures [2], [4]. Thus, reconfigurability is a particularly important type of changeability that contributes to the resolution of the production polylemma through both efficient adaption to dynamic functionality and capacity requirements over the system's lifetime, as well as customized flexibility on demand to resolve the scale and scope trade-off [2].

Designing changeable and reconfigurable manufacturing systems requires three fundamental activities; 1) identification of the system's lifetime requirements and drivers of change, 2) development of system design concepts with the right enablers and degree of change, and 3) development of a detailed system solution that embeds and realizes the required combination of change enablers [5]. In other words, the design of changeable and reconfigurable manufacturing systems takes outset in selecting the right combinations of enablers to improve changeability and enhance performance of the manufacturing system [6], [7]. However, in previous research, enablers of change such as the reconfigurability enablers are predominately regarded individually and on rather abstract levels with only limited consideration of their inherent relations when being implemented [5], [6], [8]. Moreover, the actual impact of their implementation in manufacturing systems is usually regarded on rather conceptual levels without empirical evidence, e.g. in terms of theoretically anticipated performance improvement such as lifetime cost, productivity, reconfiguration time, profitability, ramp-up time, etc. [2], [9]. Therefore, the objective of the research presented in this paper is to understand and explore implementation relations between enablers of reconfigurability and the relations between their implementation and manufacturing performance, through empirical data from a questionnaire-based survey conducted in various Danish manufacturing companies. The remainder of the paper is structured as follows; Section 2 presents the background on changeability and reconfigurability enablers, Section 3 outlines the survey research method applied, Section 4 presents the results of the research, whereas Section 5 and Section 6 conclusively discuss findings, practical implications, and viable future research directions. 


\section{Background}

The notion of changeability covers both flexibility and reconfigurability [1]. However, as described in the previous section, the importance of reconfigurability should be emphasized, due to its ability to contribute to resolution of the production poly-lemma. Therefore, this paper only addresses reconfigurability enablers of change.

The concept of the reconfigurable manufacturing system (RMS) was initially coined by Koren [10], including the six RMS core characteristics distinguished as being either necessary or supportive [2]. Scalability, convertibility, and customization are necessary characteristics, whereas modularity, integrability, and diagnosability are supportive characteristics. In recent seminal work by Wiendahl and ElMaraghy [1], these RMS characteristics were in combination with automatibility and mobility considered physical enablers of changeability on manufacturing system and assembly level. Additional high-level enablers of logical change have been proposed as well, e.g. cognitivability, adjustability, evolvability, neutrality, etc. [1]. However, since a fundamental aspect of reconfigurability is physical alterations of system structures and processes, focus will be on the physical enablers in the remainder of this paper. Table 1 outlines the aforementioned enablers of reconfigurability that are well-accepted in previous research.

Table 1. Enablers of reconfigurability.

\begin{tabular}{ll}
\hline Enabler & Description \\
\hline Scalability & $\begin{array}{l}\text { Capacity can be easily and efficiently increased or reduced. } \\
\text { Convertibility }\end{array}$ \\
& $\begin{array}{l}\text { Easy and efficient change between product variants and product } \\
\text { generations. }\end{array}$ \\
Modularity & $\begin{array}{l}\text { Major components are modular for easy and quick integration. } \\
\text { Current and future components are easily integrated through } \\
\text { standard interfaces. }\end{array}$ \\
Mobility & The ability to easily move major components. \\
Automatibility & Dynamic change of the level of automation. \\
Customization & Functionality/capacity is designed for a product family. \\
\hline
\end{tabular}

From Table 1 is its evident that a change enabler can be viewed as a construct or feature of the system that improve and enhance the system's ability to change in the desired way [1], [6], [7]. Therefore, change enablers play a fundamental role in the design process of reconfigurable manufacturing systems. In this process, the right change enablers must first of all be selected in accordance with the requirement of change identified through the change enablers [5]. Secondly, decisions on how to realize the change enablers must be made, which involves considering on which structuring level they should be implemented and in which system elements they should be embedded [5]. Consequently, designing changeable and reconfigurable manufacturing systems that embed the right enablers is a complex task, as enablers are numerous and can be implemented in various ways to enhance system performance and ability to change in the desired way. In regard to this, there are two issues related to reconfigurability enablers that are 
neglected in previous research; enablers are considered mostly on rather aggregate levels without consideration of their relation when implemented and without consideration of their relations to manufacturing performance.

Napoleone et al. [9] propose a framework where modularity and integrability enable scalability and convertibility, which then influence customization. The framework is composed based on a review of literature and thus expresses commonly anticipated enabler relations initially proposed by Koren [2], [10]; system structures that are modular and has integrability are supportive for scalability and convertibility. Hawer et al. [6] consider interdependencies between changeability enablers through fuzzy cognitive maps and validate proposed relations through an expert survey. However, such examples of explicit consideration of enabler relations with empirical evidence are limited in previous research, which results in lack of support for selecting the right enabler combinations during design of reconfigurable systems in practice. Moreover, in previous research, the question of how reconfigurability enhance performance is mostly addressed conceptually, e.g. in terms of enabler impact on reconfiguration time, productivity, and life-cycle cost [2], in terms of a broad analytical comparison [11], or in terms of more quantitatively analytical approaches [12]. However, previous research does not explicitly address the actual manufacturing performance impact of reconfigurability enabler implementation, which limits knowledge on how to select enablers during design in order to enhance performance and changeability. Therefore, the objective of this paper is to empirically explore implementation relations between enablers of reconfigurability, as well as their relations to manufacturing performance.

\section{Survey Research Method}

In order to address the objective stated above, an exploratory questionnaire-based survey method was applied. In Table 2, latent constructs and all measured items from the questionnaire are listed. The latent constructs ( RE1-RE7) represent the reconfigurability enablers from Table 1 . As these are defined on a rather aggregate and theoretical level, different measurable items have been defined accordingly. Thus, each latent construct is measured by two items; one related to its implementation on equipment level and one related to its implementation on system/line level. Only construct RE6 is defined solely for system level and not equipment level. In the questionnaire, these items were rated by respondents in terms of their level of implementation on a five-point Likert scale from "not implemented" to "fully implemented". The latent constructs (MP1-MP7) represent well-established financial performance aspects that relate to manufacturing. These items were measured in terms of level of perceived performance relative to competitors on a five-point Likert from "significantly poorer" to "significantly better”. For all items, “uncertain” responses were also possible.

In order to collect responses, the questionnaire was distributed to production specialists, engineers, operations managers, plant superiors, and managers with production responsibilities in various Danish manufacturing companies. The resulting sample contained 50 responses from different industries, which were almost equally spread between large and small/medium sized enterprises. 
Table 2. Variables in questionnaire on reconfigurability enablers and performance.

\begin{tabular}{|c|c|}
\hline $\begin{array}{l}\text { Latent } \\
\text { construct }\end{array}$ & Measured variable \\
\hline $\begin{array}{l}\text { RE1: Modu- } \\
\text { larity }\end{array}$ & $\begin{array}{l}\text { Item1: Production equipment has modular structures and contains } \\
\text { "common building blocks" that can be easily replaced or upgraded. } \\
\text { Item2: All major components of the production lines are modular } \\
\text { and contain "common building blocks" that can be easily added, re- } \\
\text { moved or upgraded. }\end{array}$ \\
\hline $\begin{array}{l}\text { RE2: Inte- } \\
\text { grability }\end{array}$ & $\begin{array}{l}\text { Item3: Components of the production equipment can be easily inte- } \\
\text { grated through standard interfaces. } \\
\text { Item4: Components of the production lines can be easily integrated } \\
\text { through standard interfaces. }\end{array}$ \\
\hline $\begin{array}{l}\text { RE3: Cus- } \\
\text { tomization }\end{array}$ & $\begin{array}{l}\text { Item5: Production equipment is designed for processing a family of } \\
\text { parts/products rather than only a single part/product. } \\
\text { Item6: Production lines are designed for producing a family of } \\
\text { products rather than a single product on the same line. }\end{array}$ \\
\hline $\begin{array}{l}\text { RE4: Scala- } \\
\text { bility }\end{array}$ & $\begin{array}{l}\text { Item7: Production equipment allows for changing production rate. } \\
\text { Item8: Production lines are built in small units, so that the line can } \\
\text { increase and decrease capacity in small increments. }\end{array}$ \\
\hline $\begin{array}{l}\text { RE5: Con- } \\
\text { vertibility }\end{array}$ & $\begin{array}{l}\text { Item9: Production equipment is designed for easy conversion be- } \\
\text { tween different tasks. } \\
\text { Item10: The production lines can be easily converted in physical } \\
\text { structure between different operating tasks. }\end{array}$ \\
\hline $\begin{array}{l}\text { RE6: Au- } \\
\text { tomatibility }\end{array}$ & $\begin{array}{l}\text { Item11: The production lines can increase and decrease the degree } \\
\text { of automation, e.g. utilizing manual, semi-automatic and fully auto- } \\
\text { matic solutions over time. }\end{array}$ \\
\hline $\begin{array}{l}\text { RE7: Mobil- } \\
\text { ity }\end{array}$ & $\begin{array}{l}\text { Item12: Production equipment can be moved around to operate at } \\
\text { different positions along the production line. } \\
\text { Item13: The production lines can be moved to different locations, } \\
\text { e.g. within the production plant or to different plants. }\end{array}$ \\
\hline $\begin{array}{l}\text { MP1: Sales } \\
\text { growth }\end{array}$ & $\begin{array}{l}\text { Item14: Sales growth relative to competitors throughout the last 3-5 } \\
\text { years }\end{array}$ \\
\hline $\begin{array}{l}\text { MP2: Profit- } \\
\text { ability }\end{array}$ & $\begin{array}{l}\text { Item15: Profitability relative to competitors throughout the last 3-5 } \\
\text { years }\end{array}$ \\
\hline $\begin{array}{l}\text { MP3: Time- } \\
\text { to-market }\end{array}$ & $\begin{array}{l}\text { Item16: Time to market relative to competitors throughout the last } \\
\text { 3-5 years }\end{array}$ \\
\hline $\begin{array}{l}\text { MP4: New } \\
\text { product suc- } \\
\text { cess }\end{array}$ & $\begin{array}{l}\text { Item17: New product success by sales volume relative to competi- } \\
\text { tors throughout the last 3-5 years }\end{array}$ \\
\hline $\begin{array}{l}\text { MP5: Mar- } \\
\text { ket share }\end{array}$ & $\begin{array}{l}\text { Item18: Market share relative to competitors throughout the last 3- } \\
5 \text { years }\end{array}$ \\
\hline $\begin{array}{l}\text { MP6: Life- } \\
\text { time of sys- } \\
\text { tems }\end{array}$ & $\begin{array}{l}\text { Item19: Lifetime of production systems and equipment relative to } \\
\text { competitors throughout the last 3-5 years }\end{array}$ \\
\hline $\begin{array}{l}\text { MP7: Ramp- } \\
\text { up time }\end{array}$ & $\begin{array}{l}\text { Item20: Ramp-up time of new products relative to competitors } \\
\text { throughout the last 3-5 years }\end{array}$ \\
\hline
\end{tabular}




\section{$4 \quad$ Results}

As a first step in analyzing the collected data, the quality of measurement items was evaluated showing adequate Cronbach alpha values above $\mathrm{C} \alpha \geq 0.7$. Secondly, data was checked for parametric assumptions of normality and homogeneity. However, both Kolmogorov-Smirnov test with $\mathrm{p} \leq 0.05$ and Shapiro-Wilk test with $\mathrm{p} \leq 0.05$ showed non-normally distributed data. Thus, non-parametric correlation analysis using Spearman's correlation coefficient was used for the subsequent data analysis. As the collected data included a few missing values from uncertain responses and due to some use of multi-item measures, relative importance indices (RIIs) were calculated for each latent construct in Table 2. These indices were used for the correlation test, where a correlation was deemed significant at $\mathrm{p} \leq 0.05$. In Table 3 , the results of the correlation analysis between reconfigurability enabler implementations are reported. Likewise, the correlations between reconfigurability enabler implementation and performance are similarly reported in Table 4.

Table 3. Correlation coefficients for reconfigurability enablers. Significance level is indicated by $* *$ for 0.01 and * for 0.05 . Italic indicates strong correlation $\geq 0.6$.

\begin{tabular}{llllllll}
\hline & RE1 & RE2 & RE3 & RE4 & RE5 & RE6 & RE7 \\
\hline RE1 & & & & & & & \\
RE2 & $.724^{* *}$ & & & & & & \\
RE3 & $.559^{* *}$ & $.337^{*}$ & & & & & \\
RE4 & $.655^{* *}$ & $.344^{*}$ & $.504^{* *}$ & & & & \\
RE5 & $.708^{* *}$ & $.397^{* *}$ & $.379^{* *}$ & $.744^{* *}$ & & & \\
RE6 & $.580^{* *}$ & $.523^{* *}$ & $.350^{* *}$ & $.426^{* *}$ & $.565^{* *}$ & & \\
RE7 & $.668^{* *}$ & $.520^{* *}$ & $.762^{* *}$ & $.502^{* *}$ & $.553^{* *}$ & $.528^{* *}$ & \\
\hline
\end{tabular}

Table 4. Correlation coefficients for reconfigurability enablers and performance. Significance is indicated by $* *$ for 0.01 and $*$ for 0.05 . Italic indicates moderate correlation $\geq 0.4$.

\begin{tabular}{llllllll}
\hline & RE1 & RE2 & RE3 & RE4 & RE5 & RE6 & RE7 \\
\hline MP1 & $.294^{*}$ & .087 & .133 & $.261^{*}$ & $.300^{*}$ & .181 & .104 \\
MP2 & $.337^{*}$ & $.396^{* *}$ & $.433^{* *}$ & .217 & .142 & $.411^{* *}$ & $.382^{* *}$ \\
MP3 & .242 & $.274^{*}$ & .145 & .069 & .215 & -.002 & .232 \\
MP4 & .202 & .19 & -.127 & .209 & $.349^{*}$ & .115 & -.1 \\
MP5 & .235 & .143 & .168 & .178 & $.286^{*}$ & .073 & .129 \\
MP6 & .233 & .161 & .231 & $.391^{* *}$ & $.423^{* *}$ & .235 & .261 \\
MP7 & $.285^{*}$ & .165 & .232 & .232 & $.386^{* *}$ & $.354^{*}$ & .252 \\
\hline
\end{tabular}

\section{Discussion}

The aim of the correlation analysis presented here was to explore implementation relations between enablers of reconfigurability, as well as their relation to performance benefits usually associated with reconfigurability. In regard to the relations between 
reconfigurability enablers, the analysis indicates the strength of the link between the degree of implementation of each pair of reconfigurability enablers. Thus, the results in Table 3 indicate that most enabler implementations correlate strongly or moderately, e.g. the implementation of modularity is to different extents positively linked to the implementation of all remaining enablers. Generally, all correlations indicate significant positive associations, where particularly strong positive links exist between the implementation of modularity and the implementation of integrability, scalability, convertibility, and mobility respectively. These findings generally confirm the notion of modularity being a fundamental and supportive enabler or characteristic that is likely to lead to reconfigurability in terms of convertibility and scalability [2], [9].

In regard to the relations between implementation of reconfigurability enablers and manufacturing performance, the results in Table 4 indicate some significant positive correlations, however, most of these only to a weak or moderate extent. The strongest significant relations exist between customization and profitability, between convertibility and life-time of systems, and between automatibility and profitability. Generally, profitability appears to have either weak of moderate correlation to most reconfigurability enablers. More notably, the implementation of convertibility seems to be positively correlated to new product success, life-time of systems, and ramp-up time of new products. This finding underpins the potential and benefits of reconfigurability for reusing production systems based process platforms that can be dynamically changed throughout the system's lifetime to suit new processing requirements, rather than designing and developing dedicated systems that become obsolete with market and product changes [2]. Similarly, the findings in Table 4 indicate that scalability is positively linked to life-time of production systems, which supports the notion of dynamic systems that can scale capacity in accordance with demand in a "pay-as-you-grow" way. Thus, the results of the pairwise analysis of implementation of reconfigurability enablers and different performance aspects generally support anticipated performance impacts of reconfigurability and changeability stated in previous research [2], [11]. Nevertheless, it should be considered that the findings reported in both Table 3 and Table 4 are based on a rather small sample of 50 respondents, which should be further increased to make more valid conclusions. Thus, the findings from the explorative survey presented here should merely be regarded as initial empirical insight into the topic of reconfigurability enabler relations and their impact on performance, leading to further possibilities and new directions of research.

\section{Conclusion}

In this paper, relations between reconfigurability enabler implementations and manufacturing performance were explored through a questionnaire-based survey in Danish manufacturing companies. The results indicate that reconfigurability enablers in general correlate strongly and positively in their implementation, and that positive links between implementation of reconfigurability enablers and performance aspects such as profitability, ramp-up time, and life-time of production systems can be identified. However, these findings merely provide initial insight into the topic of how to better support 
the design of changeable and reconfigurable manufacturing systems, taking outset in the issue of selecting the right enabler combinations that improve changeability and enhance performance. Therefore, future research should to higher extent address the inherent interdependencies between reconfigurability enablers, rather than addressing them individually and on rather abstract levels. Moreover, as previous research is limited in terms of empirical evidence of how reconfigurability enhances manufacturing performance, the findings reported in this paper should be further explored, e.g. through larger surveys or case-studies of successful reconfigurability implementations.

\section{References}

1. Wiendahl, H., ElMaraghy, H. A., Nyhuis, P. et al.: Changeable ManufacturingClassification, Design and Operation. CIRP Annals-Manufacturing Technology 56(2), 783-809 (2007)

2. Koren, Y.: General RMS characteristics. Comparison with dedicated and flexible systems. In: ElMaraghy, H.A. (ed.) Reconfigurable manufacturing systems and transformable factories, pp. 27-45. Springer (2006)

3. Brecher, C., Jeschke, S., Schuh, G. et al.: Integrative production technology for high-wage countries. Springer (2012)

4. ElMaraghy, H. A.: Flexible and Reconfigurable Manufacturing Systems Paradigms. International journal of flexible manufacturing systems 17(4), 261-276 (2005)

5. Andersen, A., ElMaraghy, H., ElMaraghy, W. et al.: A Participatory Systems Design Methodology for Changeable Manufacturing Systems. International Journal of Production Research 56(8), 1-19 (2018)

6. Hawer, S., Braun, N., Reinhart, G.: Analyzing Interdependencies between Factory Change Enablers Applying Fuzzy Cognitive Maps. Procedia CIRP 52, 151-156 (2016)

7. Rösiö, C.: Considering reconfigurability characteristics in production system design. In: ElMaraghy, H. (ed.) Enabling Manufacturing Competitiveness and Economic Sustainability, pp. 57-62. Springer (2012)

8. Russo Spena, P., Holzner, P., Rauch, E. et al.: Requirements for the Design of Flexible and Changeable Manufacturing and Assembly Systems: A SME-Survey. Procedia CIRP 41, 207-212 (2016)

9. Napoleone, A., Pozzetti, A., Macchi, M.: A Framework to Manage Reconfigurability in Manufacturing. Int J Prod Res , 1-23 (2018)

10. Koren, Y., Heisel, U., Jovane, F. et al.: Reconfigurable Manufacturing Systems. CIRP Annals-Manufacturing Technology 48(2), 527-540 (1999)

11. Zhang, G., Liu, R., Gong, L. et al.: An analytical comparison on cost and performance among DMS, AMS, FMS and RMS. In: Dashcenko, A.I. (ed.) Reconfigurable manufacturing systems and transformable factories, pp. 659-673. Springer (2006)

12. Niroomand, I., Kuzgunkaya, O., Bulgak, A. A.: The Effect of System Configuration and Ramp-Up Time on Manufacturing System Acquisition Under Uncertain Demand. Comput. Ind. Eng. 73, 61-74 (2014) 